\title{
Structural Differences Influence Biological Properties of Glucosylceramides from Clinical and Environmental Isolates of Scedosporium aurantiacum and Pseudallescheria minutispora
}

\author{
Adriana Caneppa ${ }^{1}$, Jardel Vieira de Meirelles ${ }^{1}$, Rodrigo Rollin-Pinheiro ${ }^{1} \mathbb{D}$, \\ Mariana Ingrid Dutra da Silva Xisto ${ }^{1}$, Livia Cristina Liporagi-Lopes ${ }^{2}$, Lauro de Souza ${ }^{3}$, \\ Maria Teresa Villela Romanos ${ }^{4}$ and Eliana Barreto-Bergter ${ }^{1, *}$ \\ 1 Departamento de Microbiologia Geral, Instituto de Microbiologia Professor Paulo de Góes, \\ Universidade Federal do Rio de Janeiro, Rio de Janeiro/RJ 21941-901, Brazil \\ 2 Departamento de Análises Clínicas e Toxicológicas, Faculdade de Farmácia, \\ Universidade Federal do Rio de Janeiro, Rio de Janeiro/RJ 21941-901, Brazil \\ 3 Departamento de Bioquímica e Biologia Molecular, Universidade Federal do Paraná, \\ Curitiba/PR 81531-980, Brazil \\ 4 Departamento de Virologia, Instituto de Microbiologia Professor Paulo de Góes, \\ Universidade Federal do Rio de Janeiro, Rio de Janeiro/RJ 21941-901, Brazil \\ * Correspondence: eliana.bergter@micro.ufrj.br
}

Received: 31 May 2019; Accepted: 12 July 2019; Published: 15 July 2019

\begin{abstract}
Scedosporium/Lomentospora complex is composed of filamentous fungi, including some clinically relevant species, such as Pseudallescheria boydii, Scedosporium aurantiacum, and Scedosporium apiospermum. Glucosylceramide (GlcCer), a conserved neutral glycosphingolipid, has been described as an important cell surface molecule playing a role in fungal morphological transition and pathogenesis. The present work aimed at the evaluation of GlcCer structures in S. aurantiacum and Pseudallescheria minutispora, a clinical and an environmental isolate, respectively, in order to determine their participation in fungal growth and host-pathogen interactions. Structural analysis by positive ion-mode ESI-MS (electrospray ionization mass spectrometer) revealed the presence of different ceramide moieties in GlcCer in these species. Monoclonal antibodies against Aspergillus fumigatus GlcCer could recognize S. aurantiacum and P. minutispora conidia, suggesting a conserved epitope in fungal GlcCer. In addition, these antibodies reduced fungal viability, enhanced conidia phagocytosis by macrophages, and decreased fungal survival inside phagocytic cells. Purified GlcCer from both species led to macrophage activation, increasing cell viability as well as nitric oxide and superoxide production in different proportions between the two species. These results evidenced some important properties of GlcCer from species of the Scedosporium/Lomentospora complex, as well as the effects of monoclonal anti-GlcCer antibodies on fungal cells and host-pathogen interaction. The differences between the two species regarding the observed biological properties suggest that variation in GlcCer structures and strain origin could interfere in the role of GlcCer in host-pathogen interaction.
\end{abstract}

Keywords: Scedosporium; Glucosylceramide; Host-Pathogen Interaction

\section{Introduction}

The Scedosporium/Lomentospora complex consists of filamentous fungi with a worldwide distribution and association with areas impacted by humans, such as sewage and polluted soils [1-3]. Some species are clinically relevant, with Pseudallescheria boydii, Scedosporium aurantiacum, and Scedosporium 
apiospermum, being the most prevalent. Scedosporium/Lomentospora infections found in patients $[4,5]$ consist of a broad spectrum of pathologies, ranging from superficial to invasive as well as disseminated infections [1]. On the other hand, some species are typically environmental, such as Pseudallescheria minutispora, Pseudallescheria angusta, and Pseudallescheria ellipsoidea, which are rarely associated with human infections and mostly found in soil and water [4,5].

Glucosylceramides (GlcCer) are neutral glycosphingolipids composed of a fatty acid chain and a sugar unit bound to a sphingoid base [6,7]. During the last two decades, GlcCer has been extensively described in a variety of fungi, such as Collectotrichum gloeosporioides, Fonsecaea pedrosoi, Cryptococcus neoformans, Candida albicans, and different species from the Scedosporium/Lomentospora complex [8-14]. These molecules have also been described in different Aspergillus species, such as Aspergillus fumigatus, Aspergillus oryzae, Aspergillus sojae, Aspergillus luchuensis, and Aspergillus awamori, presenting not only glucosylceramide but also galactosylceramides, showing that chemical composition may vary among fungi [15-17]. GlcCer has been shown to be a highly conserved structure among these fungi and to exert crucial roles in fungal morphological transitions, growth, and pathogenesis [8-14]. Moreover, GlcCer has been described to activate the host immune system during C. neoformans infection [18].

GlcCer from Scedosporium/Lomentospora complex has been extensively studied, and it has been already identified in different $P$. boydii strains, S. apiospermum, P. angusta, P. ellipsoidea, and Lomentospora prolificans [12-14,19]. The major structures found are composed of a glucose unit and fatty acid chain varying in length (C-16 or C-18) and degree of unsaturation. GlcCer is an important molecule for the germination process of P. boydii and S. apiospermum and for host-pathogen interaction and recognition by the host immune system $[12,13]$. The use of anti-GlcCer monoclonal antibodies (Mab) has also been described as a useful tool to localize GlcCer on the fungal cell surface and to enhance phagocytosis and killing by macrophages, presenting a protective effect for mammalian hosts [12,13].

Despite extensive studies on GlcCer over the last decades, it has never been evaluated whether the structural variation found in this molecule could influence its biological properties. In this context, this work characterized, for the first time, GlcCer from a clinical (Scedosporium aurantiacum) and an environmental (Pseudallescheria minutispora) isolate, and showed the roles of these glycosphingolipids in fungal growth, virulence, and host-pathogen interaction.

\section{Materials and Methods}

\subsection{Microorganisms and Growth Conditions}

Scedosporium aurantiacum IHEM 21147, a clinical strain isolated from an ulcer at the ankle region, and Pseudallescheria minutispora IHEM 21148, an environmental strain isolated from river sediment were used in this work. Cells were kept on Sabouraud (SAB; $2 \%$ glucose, $1 \%$ peptone, $0.5 \%$ yeast extract) agar slants as a stock culture. Mycelia were obtained by growing cells in SAB liquid culture medium for seven days at room temperature with shaking. Conidia were obtained by growing cells at $30{ }^{\circ} \mathrm{C}$ on $\mathrm{SAB}$ agar medium for seven days. Then, the plate surface was rinsed with phosphate-buffered saline (pH 7.2) (PBS; $10 \mathrm{mM} \mathrm{NaH} \mathrm{PO}_{4}, 10 \mathrm{mM} \mathrm{Na}_{2} \mathrm{HPO}_{4}, 150 \mathrm{mM} \mathrm{NaCl}$ ), and the suspension was filtered through a cell strainer to remove hyphal fragments and debris. The conidia were washed three times in PBS (pH 7.2) and counted in a Neubauer chamber.

\subsection{Mice and Peritoneal Macrophage Obtention}

Balb/C mice came from the Universidade Federal do Rio de Janeiro Breeding Unit (Rio de Janeiro, Brazil). They were kept at $25^{\circ} \mathrm{C}$ with free access to food and water in a $12 \mathrm{~h} \mathrm{light/dark} \mathrm{cycle.} \mathrm{The} \mathrm{study}$ was approved by the Institutional Committee for Animal Care and Experimentation of the Federal University of Rio de Janeiro, Rio de Janeiro, Brazil, Process Number 01200.001568/2013-87 (Comissão de Ética no Uso de Animais (CEUA) em Experimentação Científica do Centro de Ciências da Saúde da Universidade Federal do Rio de Janeiro registered at Conselho Nacional de Controle de Experimentação Animal (CONCEA)). 
Peritoneal macrophages from male BALB/c mice (4-8 weeks old) were cultured in RPMI 1640 medium supplemented with $10 \%$ bovine fetal serum. Cells were counted in a Neubauer chamber, and trypan blue vital dye exclusion was used to check viability.

\subsection{Extraction and Purification of GlcCer from S. aurantiacum and P. minutispora}

S. aurantiacum and P. minutispora mycelia were cultivated at room temperature, and total lipids were extracted using chloroform: methanol at 2:1 and 1:2 (v/v) ratios. The crude lipid extract was partitioned according to Folch and colleagues [20]. Lipids from the Folch lower layer were submitted to a silica gel column, which was sequentially eluted with chloroform, acetone, and methanol. Glycosphingolipids were detected in the acetone and methanol fractions, which were then purified by silica gel column chromatography, as described by Calixto and colleagues [14].

\subsection{ESI-MS Analysis of GlcCer from S. aurantiacum and P. minutispora}

MS analysis was performed in a Quattro-LC electrospray ionization mass spectrometer (ESI-MS) (Waters, Milford, MA, USA) with a triple-quadrupole mass analyzer operating at atmospheric pressure ionization (API) and assisted by a syringe pump (KD Scientific, Holliston, MA, USA) for sample infusion, according to Xisto and colleagues [19].

\subsection{Generation of Mab Anti-GlcCer from A. fumigatus}

Monoclonal antibodies against GlcCer were produced by immunizing six-week-old female BALB/c mice with purified GlcCer from A. fumigatus, as previously described [10].

\subsection{Immunofluorescence Analysis}

S. aurantiacum and P. minutispora cells, fixed in $4 \%$ paraformaldehyde cacodylate buffer $(0.1 \mathrm{M}$, $\mathrm{pH}$ 7.2) for $1 \mathrm{~h}$ at room temperature, were blocked using PBS-1\%BSA for $1 \mathrm{~h}$ at $37^{\circ} \mathrm{C}$. Then, either anti-GlcCer Mab or an isotype-matched control ( $50 \mathrm{mg} / \mathrm{mL}$ in PBS-1\%BSA) was used to check GlcCer exposure on the fungal surface. After washing, cells were treated with Alexa Fluor 546-conjugated donkey anti-mouse IgG (h4l) (Invitrogen Molecular Probes, Carlsbad, CA, USA) at 1:400 dilution in PBS- $1 \%$ BSA for $1 \mathrm{~h}$ at $37^{\circ} \mathrm{C}$. Cells were washed three times and suspended in $0.01 \mathrm{M} \mathrm{N}$-propyl gallate diluted in PBS: glycerol $(1: 1, v / v)$. The suspension was applied to a microscope slide, and cells were visualized using an Olympus AX70 fluorescence microscope (Olympus America Inc., Center Valley, PA, USA) using a $620 \mathrm{~nm}$ filter and a 100× magnification lens.

\subsection{Germination Assay}

The germination assay of S. aurantiacum and P. minutispora conidia in the presence of anti-GlcCer $\mathrm{Mab}$ or an unrelated IgG as control was performed according to Rollin-Pinheiro and colleagues [13]. To check cell viability, 2,3-Bis(2-methoxy-4-nitro-5-sulfophenyl)-2H-tetrazolium-5-carboxanilide inner salt (XTT, from Sigma- Aldrich Co., St. Louis, MO, USA) was added to each well, and the plates were incubated at $37^{\circ} \mathrm{C}$ for $3 \mathrm{~h}$. Then, the absorbance was measured at $570 \mathrm{~nm}$ in a spectrophotometer.

\subsection{Activation of Peritoneal Macrophages}

\subsubsection{Neutral-Red Uptake Assay}

Peritoneal macrophages were treated with S. aurantiacum or P. minutispora GlcCer (200, 100, 50, $25,12.5,6.2$, and $3.1 \mu \mathrm{g} / \mathrm{mL}$ ). After a 48 -h treatment, cell viability was measured by neutral-red dye uptake [21]. 


\subsubsection{Phagocytosis Assay}

Phagocytosis of S. aurantiacum and P. minutispora conidia by peritoneal macrophages obtained from BALB/c mice, after conidia were incubated with anti-GlcCer Mab or unrelated IgG control, was determined according to Xisto and colleagues [22]. The phagocytosis index was calculated as a ratio of the number of intracellular conidia to the number of macrophages counted.

\subsubsection{Killing Assay}

Intracellular survival of S. aurantiacum and P. minutispora conidia in peritoneal macrophages, after incubation of the conidia with anti-GlcCer Mab unrelated IgG, was evaluated according to Xisto and colleagues [22].

\subsubsection{Nitric Oxide and Superoxide Production}

Conidia and purified GlcCer were added in 96-well polystyrene tissue-culture plates containing $10^{5}$ peritoneal macrophages per well. After incubation for $2 \mathrm{~h}$ at $37{ }^{\circ} \mathrm{C}$ in the presence of $5 \% \mathrm{CO}_{2}$, aliquots from the supernatant were collected. Nitric oxide levels were measured using the Griess reagent kit (Promega, Madison, WI, USA), and superoxide dismutase activity was determined using an MTT reduction assay in which MTT is reduced to formazan by superoxide generated from macrophages. The reduction was measured in a spectrophotometer at $570 \mathrm{~nm}$. Lipopolysaccharide (LPS) and LPS inactivated by polymyxin (LPS + poly) were used as controls.

\subsection{Statistical Analysis}

Statistical analyses were done using GraphPad Prism version 5.00 for Windows (GraphPad Software, San Diego, CA, USA). One-way analysis of variance using a Kruskal-Wallis nonparametric test was used to compare the differences between groups, and individual comparisons of groups were performed using a Bonferroni posttest. The t-test was used to compare the number of colony forming units (CFU) for different groups. The $90-95 \%$ confidence interval was determined in all experiments.

\section{Results}

\subsection{Structural Analysis of P. minutispora and S. aurantiacum GlcCer}

GlcCer, purified from both P. minutispora and S. aurantiacum, is composed of a major molecular species at mass to charge ratio $(m / z) 760[\mathrm{M}+\mathrm{Li}]+$ and $m / z 734[\mathrm{M}+\mathrm{Li}]+$, respectively. (Figure $1 \mathrm{~A}, \mathrm{~B}$ ). When subjected to ESI-MS/MS, these species gave rise to major daughter ions at $m / z 598$ and 572 , corresponding to the loss of hexose (162 mass units) [M- hexose- $\mathrm{H}_{2} \mathrm{O}+\mathrm{Li}$ ]. These daughter ions were assigned to the ceramide moieties of the GlcCers species (Figure 1C,D). The ceramide ion species at $\mathrm{m} / \mathrm{z}$ 598 and $\mathrm{m} / \mathrm{z} 572$ could be assigned as $\mathrm{N}-2^{\prime}$ - hydroxyoctadecenoyl- 9-methyl-4,8-sphingadienine and $\mathrm{N}-2^{\prime}$ - hydroxyhexadecanoyl - 9-methyl- 4,8-sphingadienine, respectively (Figure 1E,F). Glucose was the only monosaccharide identified by high performance thin layer chromatography (HPTLC) after hydrolysis of the glycosphingolipids with $3 \mathrm{M}$ trifluoracetic acid (TFA) (data not shown). 
A

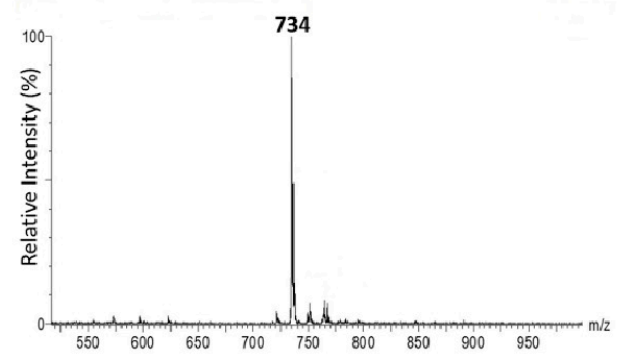

B

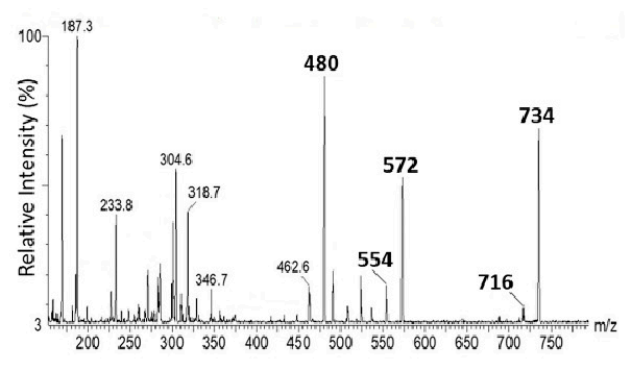

\section{C}

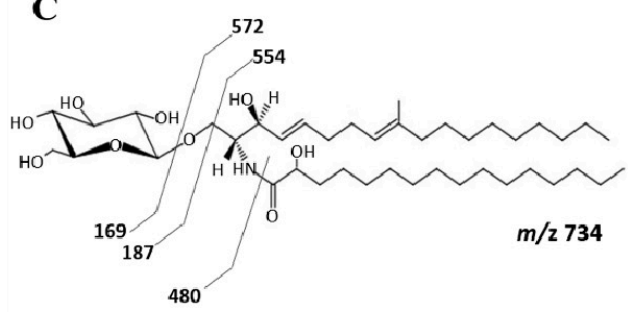

D

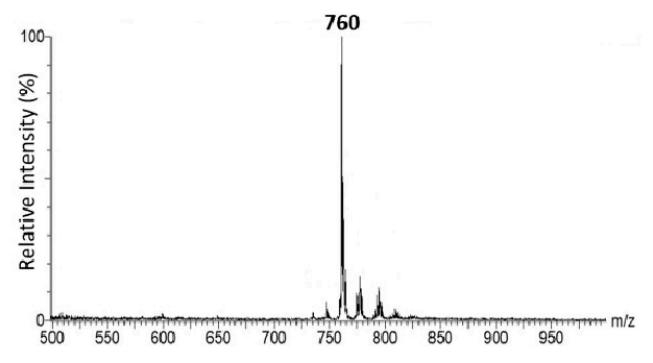

$\mathbf{E}$

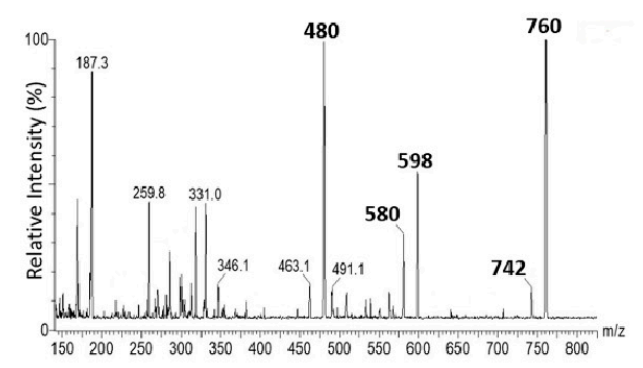

$\mathbf{F}$

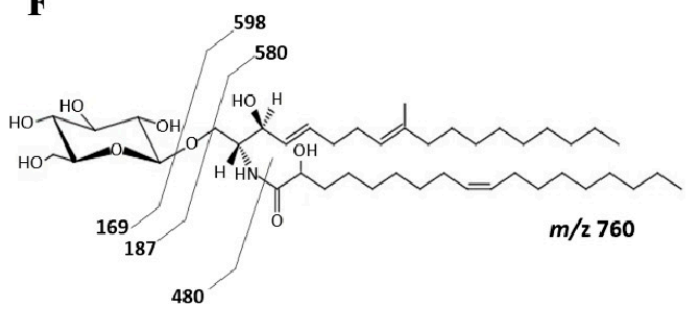

Figure 1. Positive ESI-MS (electrospray ionization mass spectrometer) [M+Li] analysis of GlcCer (Glucosylceramide) species from P. minutispora and S. aurantiacum. ESI-MS1 of GlcCer species from P. minutispora (A) and S. aurantiacum (B). ESI-MS2 of the major ion species $\mathrm{m} / \mathrm{z} 760$ (C) and $\mathrm{m} / \mathrm{z} 734$ (D). Proposed structures for P. minutispora GlcCer species (E) and S. aurantiacum GlcCer species (F).

\subsection{Binding of Mab to Fungal Cells}

Binding of Mab to S. aurantiacum and P. minutispora cells was analyzed using an indirect immunofluorescence assay. Conidia from both species were recognized by the anti-GlcCer Mab (Figure 2), indicating that GlcCer is a structure conserved between both species. Interestingly, $S$. aurantiacum germ tubes, but not those from P. minutispora, were also recognized by the Mab, suggesting that GlcCers are differently exposed on the surface of $S$. aurantiacum and P. minutispora (Figure 2C,D). 

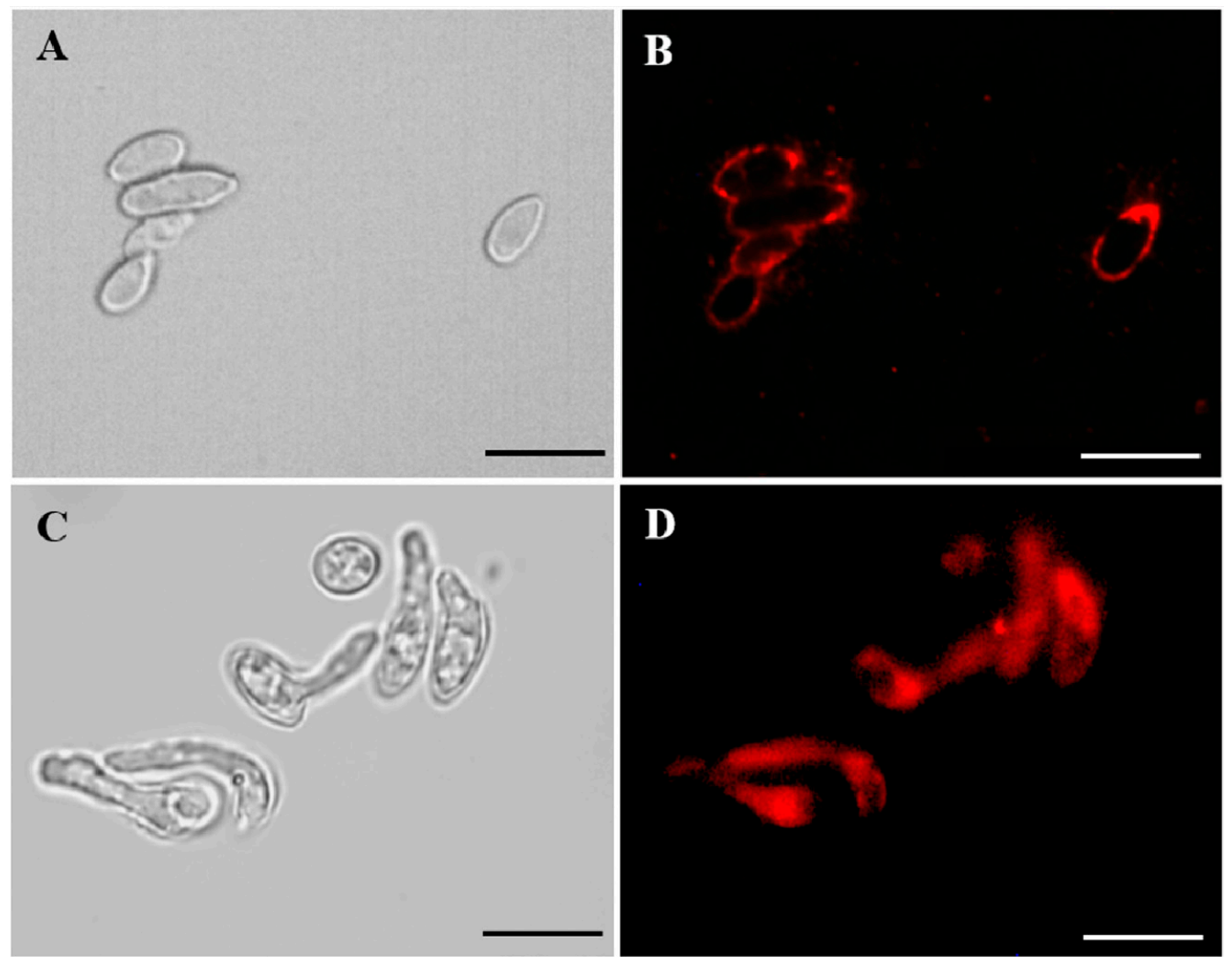

Figure 2. Indirect immunofluorescence of P. minutispora (A,B) and S.aurantiacum (C,D) conidial forms with anti-GlcCer Mab (monoclonal antibody). Differential interferential contrast microscopy (DIC) (A and $\mathbf{C}$ ) and immunofluorescence (B and D). Scale bars: $10 \mu \mathrm{m}$.

\subsection{Influence of Anti-GlcCer Mab on Fungal Differentiation and Viability}

A germination assay was performed to check whether Mab interferes in fungal morphological transition. Conidia were incubated with anti-GlcCer Mab (50,100, and $200 \mu \mathrm{g} / \mathrm{mL}$ ) for $4 \mathrm{~h}$ (S. aurantiacum) and $10 \mathrm{~h}$ (P. minutispora) since their germination time is different. Mab did not influence the germination process of S. aurantiacum and P. minutispora at any concentration tested (Figure 3A) since the conidia-mycelium transition was similar to the control level. On the other hand, the viability evaluation through MTT-reduction assay revealed decreasing cell viability at Mab concentrations of 50 and $100 \mu \mathrm{g} / \mathrm{mL}$, for S. aurantiacum, and only at $100 \mu \mathrm{g} / \mathrm{mL}$ for P. minutispora (Figure 3B). 
A

S. aurantiacum

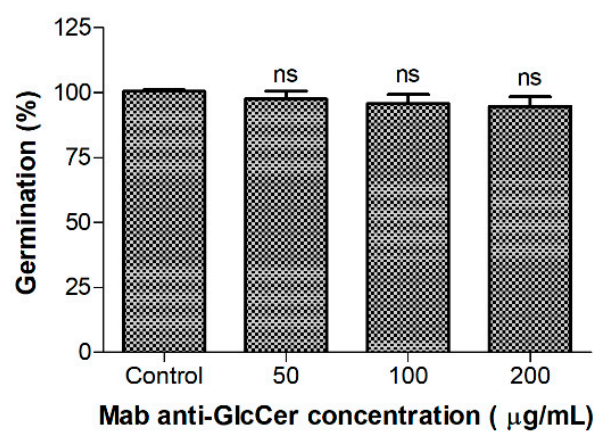

$\mathrm{C}$

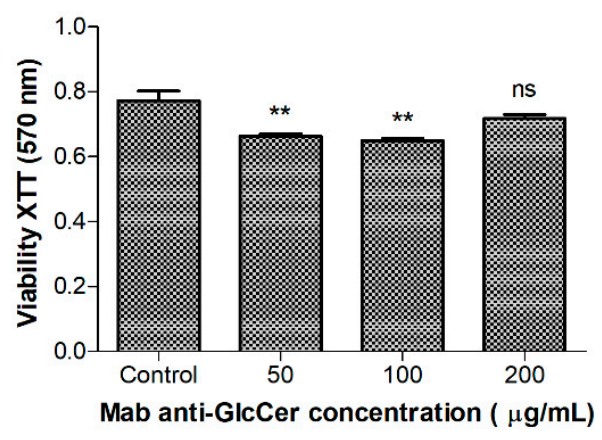

B

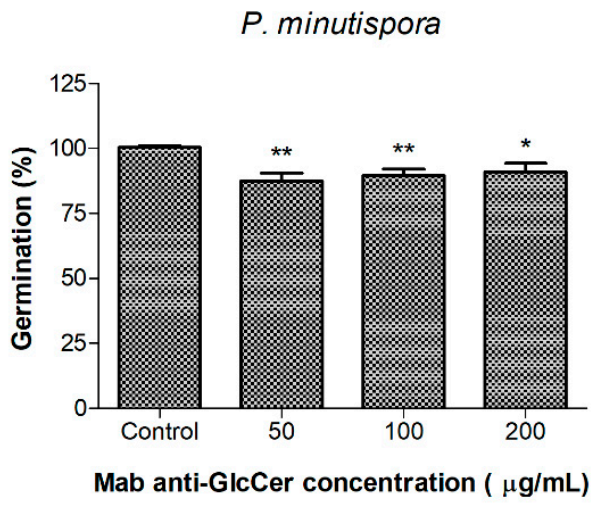

$\mathrm{D}$

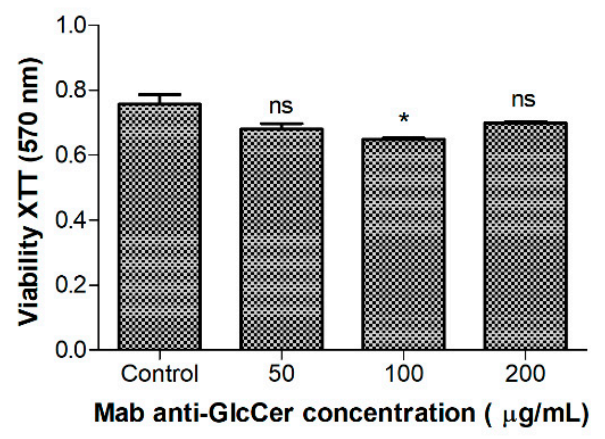

Figure 3. Effect of the anti-GlcCerMab (monoclonal antibody) on the germination and viability of conidial cells. Germinated conidia of S. aurantiacum $(\mathbf{A})$ and P. minutispora $(\mathbf{B})$ in the presence of different concentrations of anti-GlcCer Mab over $24 \mathrm{~h}$ were counted by optical microscopy. At least 100 conidia per field were counted, and the mean value of three independent counts was calculated. Viability assays were performed using S. aurantiacum (C) and P. minutispora (D) conidia and the anti-GlcCer Mab over $24 \mathrm{~h}$ and evaluated using XTT-reduction assay. The absorbance at $570 \mathrm{~nm}$ was measured using a spectrophotometer. ${ }^{*} p<0.05,{ }^{* *} p<0.03$.

\subsection{Influence of Mab Anti-GlcCer on Conidia-Peritoneal Macrophages Interaction}

In order to check whether Mab anti-GlcCer influences host-fungus interaction, phagocytosis and killing assay were performed with conidia (pre-treated or not with Mab) and mice peritoneal macrophages. Mab-treated conidia $(100 \mu \mathrm{g} / \mathrm{mL})$ significantly increased phagocytosis of S. aurantiacum and P. minutispora compared to the control, suggesting an opsonizing effect (Figure 4A). In addition, the killing assay showed that the opsonized conidia were more efficiently killed by macrophages, at all Mab concentrations for S. aurantiacum and mainly at $100 \mu \mathrm{g} / \mathrm{mL}$ of Mab for P. minutispora, indicating that anti-GlcCer Mab enhanced the antimicrobial activity of host phagocytic cells (Figure 4B). 
A

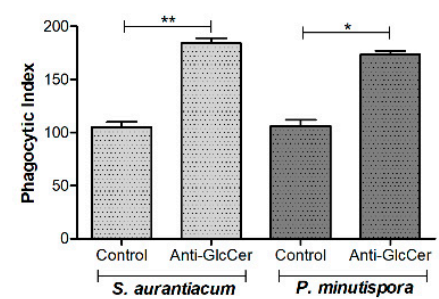

B

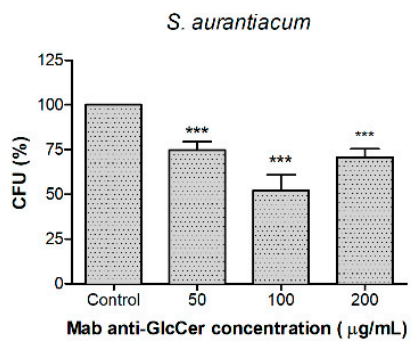

C

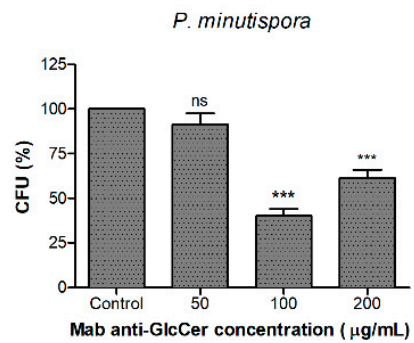

Figure 4. Influence of the anti-GlcCer (Glucosylceramide) Mab (monoclonal antibody) on the phagocytosis of conidia cells by peritoneal macrophages. (A) S. aurantiacum and P. minutispora conidia $\left(10^{6}\right)$ were incubated with 50, 100, and $200 \mathrm{ug} / \mathrm{mL}$ of Mab anti-GlcCer at $37{ }^{\circ} \mathrm{C}$ for $1 \mathrm{~h}$. Fungal cells treated with anti-GlcCer MAb were more efficiently internalized, as demonstrated by the phagocytic indices. The phagocytic index values represent the mean \pm S.D. of three independent experiments performed in triplicate. (B,C) The microbial killing of S. aurantiacum $(\mathbf{B})$ and P. minutispora (C) by macrophages was enhanced after treatment with anti-GlcCer Mab. CFU: colony forming units. ${ }^{*} p<0.05,{ }^{* *} p<0.03,{ }^{* * *} p<0.001$.

\subsection{Peritoneal Macrophages Activation by GlcCers}

To analyze whether and how GlcCers from S. aurantiacum and P. minutispora activate peritoneal macrophages, a neutral-red dye uptake assay was performed to evaluate macrophage metabolism by measuring neutral-red incorporation into lysosomes of viable cells. S. aurantiacum GlcCer increased macrophage viability at 12.5, 25, 50, 100, and $200 \mu \mathrm{g} / \mathrm{mL}$, while P. minutispora GlcCer did not alter macrophage viability at any concentration used (Figure 5). These results indicate that GlcCer from both fungi differently stimulates peritoneal macrophages.

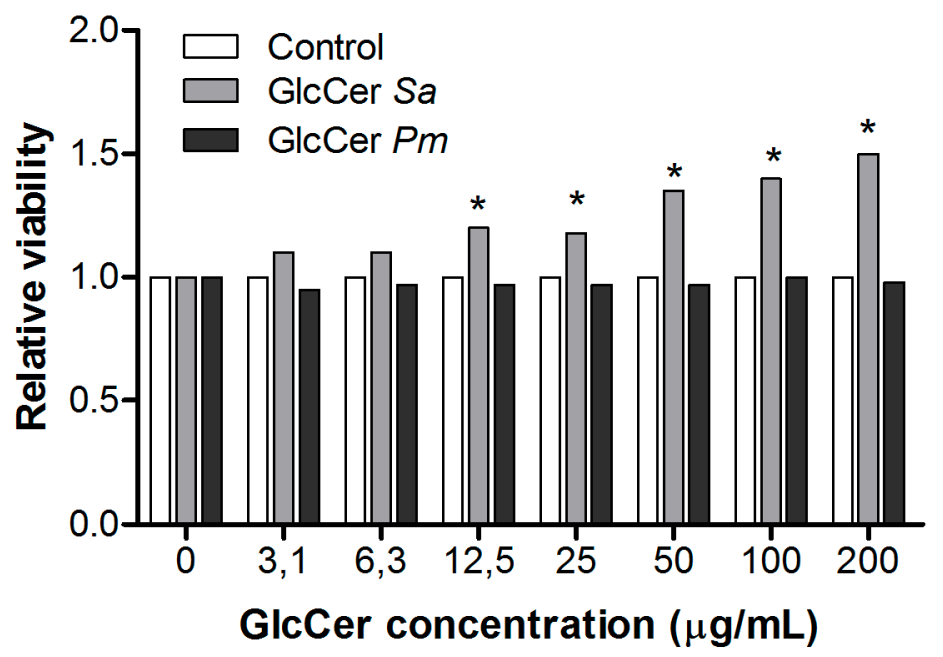

Figure 5. Peritoneal macrophages activation by purified glucosylceramides (GlcCers) from S. aurantiacum (Sa) and P. minutispora (Pm). Cell viability was measured by neutral-red dye uptake assay, and the results are presented as relative viability compared to the control. ${ }^{*} p<0.05$.

Macrophage fungicidal activity was also evaluated by nitric oxide (NO) production after incubation with S. aurantiacum and P. minutispora conidia and purified GlcCer (50 and $100 \mu \mathrm{g} / \mathrm{mL}$ ). Conidia of both fungi induced nitric oxide production. Regarding purified GlcCer, only S. aurantiacum GlcCer significantly increased nitric oxide production at 50 and $100 \mu \mathrm{g} / \mathrm{mL}$, while P. minutispora GlcCer did not significantly induce NO production, indicating that structural differences could influence NO production (Figure 6A). 
Superoxide production was also evaluated, showing that GlcCer from both fungi induced its production at 50 and $100 \mu \mathrm{g} / \mathrm{mL}$. Interestingly, only S. aurantiacum conidia increased superoxide production, while P. minutispora conidia did not alter this parameter (Figure 6B). Additionally, S. aurantiacum GlcCer induced more superoxide production compared to P. minutispora GlcCer (Figure 6B). These results indicate that variations in superoxide production are observed between species.

A

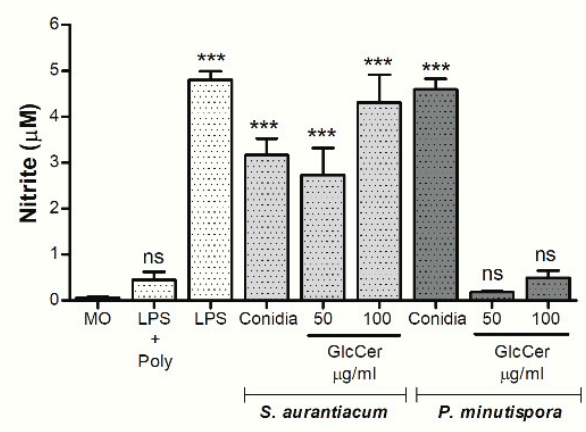

B

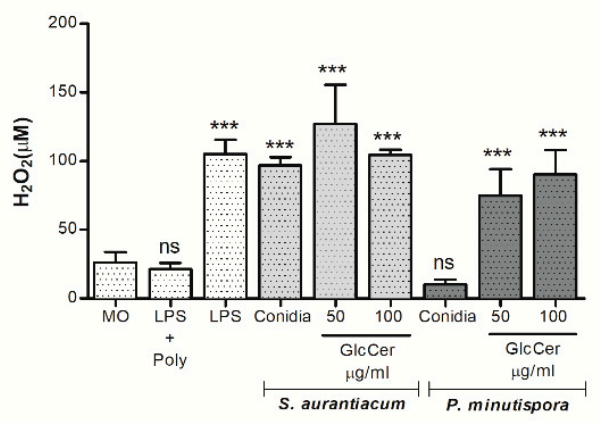

Figure 6. Activation of the oxidative burst in peritoneal macrophages. Macrophages $\left(2.5 \times 10^{5}\right)$ were incubated at $37^{\circ} \mathrm{C}$ for $2 \mathrm{~h}$ in the presence of S. aurantiacum and P. minutispora conidia, as well as 50 and $100 \mathrm{mg} / \mathrm{mL}$ of purified GlcCer (Glucosylceramide) from both fungi in order to quantify nitrite (A) and $\mathrm{H}_{2} \mathrm{O}_{2}$ (B). As positive controls, LPS (lipopolysaccharide) (10 ng/well) was used. Data are the mean of duplicate samples from four independent experiments. $p<0.001 ;+$ Poly, polymyxin added. *** $p<0.001$.

\section{Discussion}

Glucosylceramide (GlcCer) is an important molecule for fungal growth and virulence. The GlcCer structure is highly conserved among different fungal species. For Scedosporium/Lomentospora species, it has already been described in P. boydii, S. apiospermum [12,13], and L. prolificans [19]. The present work brings the first description of GlcCers in P. minutispora and S. aurantiacum. The comparison between these two species becomes relevant since P. minutispora is a typical environmental isolate with rare cases of human infections, while $S$. aurantiacum is a typical clinical isolate being considered one of the most virulent and resistant Scedosporium/Lomentospora species [4,23,24].

The major GlcCer structure found in P. minutispora $(\mathrm{m} / \mathrm{z} 760)$ has also been previously found in Fusarium species and A. fumigatus [25], whereas the one identified in S. aurantiacum $(\mathrm{m} / z$ 734) is similar to P. boydii and S. apiospemum GlcCers $[12,13]$. GlcCers isolated from other species belonging to the Scedosporium/Lomentospora complex, such as P. ellipsoidea and P. boydii, presented three molecular species at $m / z 734,750$, and 762 [14]. These data indicate that GlcCers might vary among species from Scedosporium/Lomentospora complex.

Studies performed with C. neoformans, P. boydii, S. apiospermum, P. angusta, and P. ellipsoidea using monoclonal antibodies against GlcCer described that these sphingolipids are localized on fungal surface, especially as part of the plasma membrane and cell wall [8,12-14]. Our data corroborate with the literature, since Mab anti-GlcCer recognized P. minutispora and S. aurantiacum conidia, as well as on S. aurantiacum germ tube. Interestingly, Mab anti-GlcCer is developed using purified A. fumigatus GlcCer, therefore, revealing that Mab binds to an epitope conserved among different fungal GlcCers and that differences in Mab recognition could be explained by variation in the exposition of GlcCer on the fungal surface.

It has been shown that GlcCer plays a crucial role in the fungal morphological transition, as also demonstrated for C. gloeosporioides, F. pedrosoi, C. albicans, A. fumigatus, P. boydii, and S. apiospermum [9-13]. Interestingly, the germination of P. minutispora and S. aurantiacum was not affected by Mab, similarly to what has been described for Paracoccidioides brasiliensis, Histoplasma capsulatum, and Sporothrix schenckii 
whose fungal growth rates are not affected by anti-GlcCer Mab [26]. These results are different from what is observed for S. apiospermum, in which germination is reduced by about $50 \%$, but cell viability is not affected by the Mab [13]. These data suggest that even not affecting directly the morphological transition, Mab binding to GlcCer on the cell surface can influence fungal metabolism.

Monoclonal antibodies anti-GlcCer have been shown to opsonize fungal conidia, as demonstrated in F. pedrosoi and S. apiospermum models $[13,27]$. These effects are interesting for fungal clearance since the macrophage cellular response is the most efficient to eliminate fungal infections [28]. Our data corroborate with these studies since Mab anti-GlcCer enhanced macrophages fungicidal activity against S. aurantiacum and P. minutispora. These data corroborate with the immunofluorescence and the viability assays since the binding of Mab to fungal conidia leads to its opsonization, and the decreased cell viability can contribute to lower fungal survival after macrophage phagocytosis. Bueno and colleagues have recently shown similar results for $P$. brasiliensis using polyclonal anti-glycosphingolipids antibodies, in which opsonization increased macrophage phagocytosis and reduced fungal survival [29].

Since conidia opsonization significantly influences macrophage phagocytosis and killing, we evaluated macrophage activation to check how they eliminate fungal cells. Macrophage action occurs by the release of reactive oxygen and nitrogen species, such as superoxide anions and nitric oxide, leading to fungal digestion inside phagocytic cells [28]. Acidic glycosphingolipids from P. brasiliensis also do not increase nitric oxide production [29], suggesting that each fungal species interacts differently with host immune cells depending on the variation of lipid structures. Superoxide has been described as an important substance produced by macrophages during C. neoformans clearance. However, C. neoformans presents an enzyme, superoxide dismutase, as an evasion mechanism that inactivates superoxide anions and enhances fungal virulence [30]. On the other hand, H. capsulatum is killed by bronchoalveolar macrophages through the production of other substances, such as hydrogen peroxide and nitric oxide production [31]. Although ROS production is induced by GlcCer purified from both, S. aurantiacum and P. minutispora, only conidia of S. aurantiacum result in induction. This can be due to the ability of some fungi to block ROS production by macrophages. Coccidioides can block nitric oxide production by mice macrophages treated with interferon gamma (IFN- $\gamma$ ) and LPS because of the secretion of an unknown soluble factor [32]. In addition, some fungi, such as A. fumigatus, decrease fungicidal effects in macrophages by synthetizing a superoxide dismutase that inhibits the action of superoxide anions [33], a finding that could explain why GlcCer purified from P. minutispora, but not its conidia, induces ROS production.

Interesting differences were observed between GlcCer from S. aurantiacum and P. minutispora, especially regarding the macrophage function experiments. GlcCer from S. aurantiacum induced higher macrophage cell viability, intracellular fungal clearance, and the production of fungicidal substances, such as nitric oxide and superoxide, compared to GlcCer from P. minutispora. GlcCer structure of S. aurantiacum is similar to the one found in L. prolificans, which has been also shown to stimulate host immune response [19]. On the other hand, GlcCer of P. minutispora, which induced less macrophage effector response, possesses a different ceramide containing a longer fatty acid and an unsaturation (C18:1) when compared to S. aurantiacum whose GlcCer is consisted of ceramide with shorter saturated fatty acid (C16:0). It suggests that GlcCer structure influences the stimuli promoted in immune cells. In bacteria, the lipopolysaccharide (LPS) localized in the cell wall is a well-known immune response stimulator. However, differences in LPS structure, especially in the lipid A portion, lead to higher or lower inflammatory responses [34,35]. LPS containing 10-carbon chain in lipid A displays the best cytokine induction, whereas other acyl chain length results in a different cytokine profile [36,37].

Another possible explanation for these differences in fungi-macrophage interaction is the origin of the strains used. S. aurantiacum, which induced a higher macrophage activity, is a clinical isolate, while P. minutispora is an environmental one. These results corroborate with the study of Caffrey-Carr and colleagues [38], in which the clinical strain of A. fumigatus promoted a higher interleukin $1 \alpha$ level in the lungs of infected mice compared to environmental isolates [38]. Our data suggest that the source 
of isolation (clinical or environmental) could interfere in host-pathogen interaction and, consequently, the immune response profile by the host.

Taken together, the information presented here indicates that GlcCer structure varies among fungal pathogens, and this variation could lead to different biological properties.

Author Contributions: The authors contributed to the work as following stated: conceptualization, A.C. and J.V.d.M.; methodology, A.C., J.V.d.M., R.R.-P., M.I.D.d.S.X., M.T.V.R. and L.C.L.-L.; software, L.d.S.; formal analysis, M.I.D.d.S.X.; investigation, A.C., J.V.d.M., M.T.V.R. and M.I.D.d.S.X.; resources, E.B.-B.; data curation, A.C., J.V.d.M., R.R.-P., and M.I.D.d.S.X.; writing—original draft preparation, R.R.-P., M.I.X, L.C.L.-L., and E.B.-B.; writing-review and editing, R.R.-P., M.I.X, L.C.L.-L., and E.B.-B.; supervision, E.B.-B.; project administration, E.B.-B.; funding acquisition, E.B.-B.

Funding: This study was financed in part by the Coordenação de Aperfeiçoamento de Pessoal de Nível Superior Brasil (CAPES) - Finance Code 001; Conselho Nacional de Desenvolvimento Científico e Tecnológico (CNPq) and Fundação de Amparo à Pesquisa do estado do Rio de Janeiro (Faperj).

Acknowledgments: The authors thank the Centro de Espectrometria de Massas de Biomoléculas (CEMBIO) for helping with the structural characterization of GlcCer and Walter Oelemann for English revision.

Conflicts of Interest: The authors declare no conflict of interest.

\section{References}

1. Cortez, K.J.; Roilides, E.; Quiroz-Telles, F.; Meletiadis, J.; Antachopoulos, C.; Knudsen, T.; Buchanan, W.; Milanovich, J.; Sutton, D.A.; Fothergill, A.; et al. Infections caused by Scedosporium spp. Clin. Microbiol. Rev. 2008, 21, 157-197. [CrossRef] [PubMed]

2. Rougeron, A.; Schuliar, G.; Leto, J.; Sitterle, E.; Landry, D.; Bougnoux, M.E.; Kobi, A.; Bouchara, J.P.; Giraud, S. Human-impacted areas of France are environmental reservoirs of the Pseudallescheria boydii/Scedosporium apiospermum species complex. Environ. Microbiol. 2015, 17, 1039-1048. [CrossRef] [PubMed]

3. Ramirez-Garcia, A.; Pellon, A.; Rementeria, A.; Buldain, I.; Barreto-Bergter, E.; Rollin-Pinheiro, R.; de Meirelles, J.V.; Xisto, M.; Ranque, S.; Havlicek, V.; et al. Scedosporium and Lomentospora: An updated overview of underrated opportunists. Med. Mycol. 2018, 56, 102-125. [CrossRef]

4. Kaltseis, J.; Rainer, J.; De Hoog, G.S. Ecology of Pseudallescheria and Scedosporium species in human-dominated and natural environments and their distribution in clinical samples. Med. Mycol. 2009, 47, 398-405. [CrossRef]

5. Gilgado, F.; Cano, J.; Gene, J.; Serena, C.; Guarro, J. Different virulence of the species of the Pseudallescheria boydii complex. Med. Mycol. 2009, 47, 371-374. [CrossRef]

6. Barreto-Bergter, E.; Pinto, M.R.; Rodrigues, M.L. Structure and biological functions of fungal cerebrosides. An. Acad. Bras. Cienc. 2004, 76, 67-84. [CrossRef] [PubMed]

7. Barreto-Bergter, E.; Sassaki, G.L.; de Souza, L.M. Structural analysis of fungal cerebrosides. Front. Microbiol. 2011, 2, 239. [CrossRef]

8. Rodrigues, M.L.; Travassos, L.R.; Miranda, K.R.; Franzen, A.J.; Rozental, S.; de Souza, W.; Alviano, C.S.; Barreto-Bergter, E. Human antibodies against a purified glucosylceramide from Cryptococcus neoformans inhibit cell budding and fungal growth. Infect. Immun. 2000, 68, 7049-7060. [CrossRef]

9. Nimrichter, L.; Cerqueira, M.D.; Leitao, E.A.; Miranda, K.; Nakayasu, E.S.; Almeida, S.R.; Almeida, I.C.; Alviano, C.S.; Barreto-Bergter, E.; Rodrigues, M.L. Structure, cellular distribution, antigenicity, and biological functions of Fonsecaea pedrosoi ceramide monohexosides. Infect. Immun. 2005, 73, 7860-7868. [CrossRef]

10. da Silva, A.F.C.; Rodrigues, M.L.; Farias, S.E.; Almeida, I.C.; Pinto, M.R.; Barreto-Bergter, E. Glucosylceramides in Colletotrichum gloeosporioides are involved in the differentiation of conidia into mycelial cells. FEBS Lett. 2004, 561, 137-143. [CrossRef]

11. Levery, S.B.; Momany, M.; Lindsey, R.; Toledo, M.S.; Shayman, J.A.; Fuller, M.; Brooks, K.; Doong, R.L.; Straus, A.H.; Takahashi, H.K. Disruption of the glucosylceramide biosynthetic pathway in Aspergillus nidulans and Aspergillus fumigatus by inhibitors of UDP-Glc:ceramide glucosyltransferase strongly affects spore germination, cell cycle, and hyphal growth. FEBS Lett. 2002, 525, 59-64. [CrossRef]

12. Pinto, M.R.; Rodrigues, M.L.; Travassos, L.R.; Haido, R.M.; Wait, R.; Barreto-Bergter, E. Characterization of glucosylceramides in Pseudallescheria boydii and their involvement in fungal differentiation. Glycobiology 2002, 12, 251-260. [CrossRef] [PubMed] 
13. Rollin-Pinheiro, R.; Liporagi-Lopes, L.C.; de Meirelles, J.V.; Souza, L.M.; Barreto-Bergter, E. Characterization of Scedosporium apiospermum glucosylceramides and their involvement in fungal development and macrophage functions. PLoS ONE 2014, 9, e98149. [CrossRef] [PubMed]

14. Calixto, R.O.; Rollin-Pinheiro, R.; da Silva, M.I.; Liporagi-Lopes, L.C.; Vieira, J.V.D.M.; Sassaki, G.L.; Barreto-Bergter, E. Structural analysis of glucosylceramides (GlcCer) from species of the Pseudallescheria/Scedosporium complex. Fungal Biol. 2016, 120, 166-172. [CrossRef] [PubMed]

15. Tani, Y.; Amaishi, Y.; Funatsu, T.; Ito, M.; Itonori, S.; Hata, Y.; Ashida, H.; Yamamoto, K. Structural analysis of cerebrosides from Aspergillus fungi: The existence of galactosylceramide in A. oryzae. Biotechnol. Lett. 2014, 36, 2507-2513. [CrossRef] [PubMed]

16. Fontaine, T. Sphingolipids from the human fungal pathogen Aspergillus fumigatus. Biochimie 2017, 141, 9-15. [CrossRef]

17. Takahashi, K.; Izumi, K.; Nakahata, E.; Hirata, M.; Sawada, K.; Tsuge, K.; Nagao, K.; Kitagaki, H. Quantitation and structural determination of glucosylceramides contained in sake lees. J. Oleo. Sci. 2014, 63, 15-23. [CrossRef]

18. Mor, V.; Farnoud, A.M.; Singh, A.; Rella, A.; Tanno, H.; Ishii, K.; Kawakami, K.; Sato, T.; Del Poeta, M. Glucosylceramide Administration as a Vaccination Strategy in Mouse Models of Cryptococcosis. PLoS ONE 2016, 11, e0153853. [CrossRef]

19. Xisto, M.; Henao, J.E.M.; Dias, L.D.S.; Santos, G.M.P.; Calixto, R.O.R.; Bernardino, M.C.; Taborda, C.P.; Barreto-Bergter, E. Glucosylceramides From Lomentospora prolificans Induce a Differential Production of Cytokines and Increases the Microbicidal Activity of Macrophages. Front. Microbiol. 2019, 10, 554. [CrossRef]

20. Folch, J.; Lees, M.; Sloane Stanley, G.H. A simple method for the isolation and purification of total lipides from animal tissues. J. Biol. Chem. 1957, 226, 497-509.

21. Borenfreund, E.; Puerner, J.A. Toxicity determined in vitro by morphological alterations and neutral red absorption. Toxicol. Lett. 1985, 24, 119-124. [CrossRef]

22. Xisto, M.I.; Bittencourt, V.C.; Liporagi-Lopes, L.C.; Haido, R.M.; Mendonca, M.S.; Sassaki, G.; Figueiredo, R.T.; Romanos, M.T.; Barreto-Bergter, E. O-glycosylation in cell wall proteins in Scedosporium prolificans is critical for phagocytosis and inflammatory cytokines production by macrophages. PLoS ONE 2015, 10, e0123189. [CrossRef]

23. Blyth, C.C.; Middleton, P.G.; Harun, A.; Sorrell, T.C.; Meyer, W.; Chen, S.C. Clinical associations and prevalence of Scedosporium spp. in Australian cystic fibrosis patients: Identification of novel risk factors? Med. Mycol. 2010, 48, S37-44. [CrossRef] [PubMed]

24. Kaur, J.; Duan, S.Y.; Vaas, L.A.; Penesyan, A.; Meyer, W.; Paulsen, I.T.; Nevalainen, H. Phenotypic profiling of Scedosporium aurantiacum, an opportunistic pathogen colonizing human lungs. PLoS ONE 2015, 10, e0122354. [CrossRef] [PubMed]

25. Duarte, R.S.; Polycarpo, C.R.; Wait, R.; Hartmann, R.; Bergter, E.B. Structural characterization of neutral glycosphingolipids from Fusarium species. Biochim. Biophys. Acta 1998, 1390, 186-196. [CrossRef]

26. Toledo, M.S.; Levery, S.B.; Straus, A.H.; Takahashi, H.K. Dimorphic expression of cerebrosides in the mycopathogen Sporothrix schenckii. J. Lipid Res. 2000, 41, 797-806. [PubMed]

27. Nimrichter, L.; Barreto-Bergter, E.; Mendonca-Filho, R.R.; Kneipp, L.F.; Mazzi, M.T.; Salve, P.; Farias, S.E.; Wait, R.; Alviano, C.S.; Rodrigues, M.L. A monoclonal antibody to glucosylceramide inhibits the growth of Fonsecaea pedrosoi and enhances the antifungal action of mouse macrophages. Microb. Infect. 2004, 6, 657-665. [CrossRef]

28. Roilides, E.; Simitsopoulou, M.; Katragkou, A.; Walsh, T.J. Host immune response against Scedosporium species. Med. Mycol. 2009, 47, 433-440. [CrossRef]

29. Bueno, R.A.; Thomaz, L.; Munoz, J.E.; da Silva, C.J.; Nosanchuk, J.D.; Pinto, M.R.; Travassos, L.R.; Taborda, C.P. Antibodies Against Glycolipids Enhance Antifungal Activity of Macrophages and Reduce Fungal Burden After Infection with Paracoccidioides brasiliensis. Front. Microbiol. 2016, 7, 74. [CrossRef]

30. Cox, G.M.; Harrison, T.S.; McDade, H.C.; Taborda, C.P.; Heinrich, G.; Casadevall, A.; Perfect, J.R. Superoxide dismutase influences the virulence of Cryptococcus neoformans by affecting growth within macrophages. Infect. Immun. 2003, 71, 173-180. [CrossRef]

31. Brummer, E.; Stevens, D.A. Antifungal mechanisms of activated murine bronchoalveolar or peritoneal macrophages for Histoplasma capsulatum. Clin. Exp. Immunol. 1995, 102, 65-70. [CrossRef] 
32. Gonzalez, A.; Hung, C.Y.; Cole, G.T. Coccidioides releases a soluble factor that suppresses nitric oxide production by murine primary macrophages. Microb. Pathog. 2011, 50, 100-108. [CrossRef] [PubMed]

33. Lambou, K.; Lamarre, C.; Beau, R.; Dufour, N.; Latge, J.P. Functional analysis of the superoxide dismutase family in Aspergillus fumigatus. Mol. Microbiol. 2010, 75, 910-923. [CrossRef] [PubMed]

34. Xiao, X.; Sankaranarayanan, K.; Khosla, C. Biosynthesis and structure-activity relationships of the lipid a family of glycolipids. Curr. Opin. Chem. Biol. 2017, 40, 127-137. [CrossRef] [PubMed]

35. Steimle, A.; Autenrieth, I.B.; Frick, J.S. Structure and function: Lipid A modifications in commensals and pathogens. Int. J. Med. Microbiol. 2016, 306, 290-301. [CrossRef] [PubMed]

36. Johnson, D.A.; Keegan, D.S.; Sowell, C.G.; Livesay, M.T.; Johnson, C.L.; Taubner, L.M.; Harris, A.; Myers, K.R.; Thompson, J.D.; Gustafson, G.L.; et al. 3-O-Desacyl monophosphoryl lipid A derivatives: Synthesis and immunostimulant activities. J. Med. Chem. 1999, 42, 4640-4649. [CrossRef] [PubMed]

37. Johnson, D.A. Synthetic TLR4-active glycolipids as vaccine adjuvants and stand-alone immunotherapeutics. Curr. Top. Med. Chem. 2008, 8, 64-79. [CrossRef] [PubMed]

38. Caffrey-Carr, A.K.; Kowalski, C.H.; Beattie, S.R.; Blaseg, N.A.; Upshaw, C.R.; Thammahong, A.; Lust, H.E.; Tang, Y.W.; Hohl, T.M.; Cramer, R.A.; et al. Interleukin 1alpha Is Critical for Resistance against Highly Virulent Aspergillus fumigatus Isolates. Infect. Immun. 2017, 85. [CrossRef] [PubMed]

(C) 2019 by the authors. Licensee MDPI, Basel, Switzerland. This article is an open access article distributed under the terms and conditions of the Creative Commons Attribution (CC BY) license (http://creativecommons.org/licenses/by/4.0/). 